\title{
Characteristic of Coconut-Shell Ash as Filler and LDPE Plastic Waste as Substitution Materials of Porous Asphalt Mixtures
}

\author{
Tamalkhani Syammaun, Firmansyah Rachman, Rifki Hidayat
}

\begin{abstract}
Porous asphalt is designed to have a relatively higher porosity than other pavement types, this porous property is obtained because the proportion of fine aggregate is less than other types of mixtures. In an effort to increase the strength of porous asphalt pavement structures, it is required to use other added materials both as additives, stabilizers and substitution materials. In this study, the added material used was low density polyethylene (LDPE) plastic waste as a substitute for asphalt and coconut-shell ash (CA) as filler substitution material. Stone ash, cement and fly ash are commonly used as fillers in asphalt mixture, $C A$ is expected to be one of the alternatives. This study aims to determine the characteristics of using LDPE into asphalt pen. 60/70 and the use of 50\% CA filler on the characteristics of porous asphalt mixture and to find out indications of deficiencies and strengths in the asphalt mixture. On the initial bitumen content without using substitutes, the optimum bitumen content (OAC) was $5.76 \%$ with the variation used of LDPE 3\%, 5\% and 7\% and 50\% CA as filler. At OAC value $5.76 \%$ with $3 \%$ LDPE substitution meet all required parameter. With the value of Marshall Stability, VIM, Flow, AFD, and CL are 560.50kg, $18.61 \%, 4.3 \mathrm{~mm}, 0.22 \%$ and $19.69 \%$ respectively.
\end{abstract}

Keywords: Coconut-Shell Ash, Low Density Polyethylene, Porous Asphalt, Stability.

\section{INTRODUCTION}

Road infrastructure is something very important to support social activities and improve the economy. Therefore the road improvement program is very important so that it can serve traffic developments safely and comfortably. Damage to the surface layer has an impact on the construction of pavement structures and the use of materials used.

Road damage in Indonesia generally occurs due to stagnant water originating from high rainfall which causes damage to the asphalt surface layer, therefore solutions and considerations are needed in planning asphalt mixes. One type that is developed in the road surface layer so that it can drain water inundation that occurs is porous asphalt mixture. This asphalt has a high porosity compared to other pavements, this porous property is obtained because the proportion of fine

Revised Manuscript Received on November 05, 2019.

* Correspondence Author

Tamalkhani Syammaun*, Civil Engineering Department, Engineering Faculty, University of Muhammadiyah Aceh, Banda Aceh, Indonesia. Email: tamalkhani@unmuha.ac.id

Firmansyah Rachman, Civil Engineering Department, Engineering Faculty, University of Muhammadiyah Aceh, Banda Aceh, Indonesia. Email: firmansyah@unmuha.ac.id

Rifki Hidayat, Civil Engineering Department, Engineering Faculty, University of Muhammadiyah Aceh, Banda Aceh, Indonesia. Email: rifki.hidayat@unmuha.ac.id aggregate is less than other types of mixture.

Porous asphalt has higher porosity than other types of pavement with a large amount of cavity content which results in a rather rough surface condition, so that it has high rigidity and cavities that function to pass the water in the mixture. The properties of porous asphalt is similar to the paved mixtures. It uses $70-85 \%$ coarse agregate and $15-30 \%$ fine aggregates to the total weight of the mixture which produces hollow structures [1]. Existing cavities provide the ability to flow water well for vertical and horizontal directions so that it keeps the surface layer dry.

In an effort to increase the strength of the pavement structure, it is necessary to have additional additives, stabilizers and substitutes. In this study, plastic waste with low density polyethylene (LDPE) was used as asphalt substitute and CA as filler substitute in porous asphalt mixtures so that later the characteristics of the asphalt mixture would be known.

$\mathrm{CA}$ is the remaining combustion from charcoal that has become ash, black to gray, usually odorless and tasteless. CA has a behavior to bind because it has silica oxide ( $\mathrm{SiO} 2)$ content with a percentage level of $7.40 \%$ (Industrial Research and Standardization Agency, 2010), so that this content can increase reinforcement against porous asphalt, whereas LDPE plastic waste as substitute asphalt pen. 60/70 to find out its characteristics of porous asphalt mixture.

So far from several sources reviewed, CA and LDPE plastic waste have not been utilized optimally as a substitute for porous asphalt mixtures. Therefore, both of these materials become alternatives to be used in a laboratory study to determine their effect on the characteristics of porous asphalt mixtures with the Marshall method and refer to the specifications specified by the Australian Asphalt Pavement Association [2].

Several literature studies and research related to CA and LDPE found that the asphalt mixture characteristics that use these materials still meet the requirements set by Bina Marga (2014) and AAPA (2004) [3-12].

Based on the hypothesis above, a study will be conducted on the effect of the use of CA as filler substitution material in this study, which is $50 \%$ of the total filler weight and LDPE plastic waste as asphalt pen substitution material. 60/70 of $3 \%, 5 \%$ and $7 \%$ of the total asphalt weight. There is no particular formula to get the variation of substitution that means substitution is done with several variations as a form of empirical method. 


\section{MATERIALS AND METHODOLOGY}

\section{A. Material Selection}

\section{1) Aggregate}

The broken stone for this research, is taken from PT. Ayu Lestari which is located in Indrapuri sub-district, Aceh Besar District, Aceh Province. It was tested to obtain its physical properties. The results of examination of physical properties are: examination of specific gravity, injection, weight of content, wear, flakiness index, elongated index and impact examination.

From the results of an approved examination that can be used because it meets the specified requirements. The results of examination of aggregate physical properties are presented in the following:

Table- I: Physical Properties of Aggregate

\begin{tabular}{|c|l|c|c|c|}
\hline No. & \multicolumn{1}{|c|}{$\begin{array}{c}\text { Physical } \\
\text { Properties }\end{array}$} & Unit & $\begin{array}{c}\text { Testing } \\
\text { Result }\end{array}$ & Requirement \\
\hline 1. & Specific gravity & gr/cm3 & 2,775 & Min. 2,5 \\
\hline 2. & Absorption & $\%$ & 1,119 & Mak.2 \\
\hline 3. & Unit weight & $\mathrm{Kg} / \mathrm{dm} 3$ & 1,656 & Min.1 \\
\hline 4. & Hardness & $\%$ & 8,94 & Mak.30 \\
\hline 5. & Abrasion & $\%$ & 15,00 & Mak. 40 \\
\hline 6. & Flakiness index & $\%$ & 17,18 & Mak.25 \\
\hline 7. & Elongated index & $\%$ & 15,47 & Mak.25 \\
\hline 8. & Specific gravity & gr/cm3 & 2,775 & Min. 2,5 \\
\hline
\end{tabular}

\section{2) Asphalt Binder}

Data from the test results for the physical properties of asphalt obtained after testing of asphalt penetration 60/70 produced by PT. Pertamina which was used as material in this study. The results of examination of physical properties, namely, specific gravity, penetration, ductility, and softening point.

The results of the examination show that the asphalt can be used because it fulfils the requirements set. The results of examination of the physical properties of asphalt penetration $60 / 70$ are presented in table below:

Table- II: Physical Properties of Aggregate

\begin{tabular}{|c|l|c|c|c|c|c|c|}
\hline \multirow{2}{*}{ No } & \multirow{2}{*}{$\begin{array}{c}\text { Physical } \\
\text { Properties }\end{array}$} & \multicolumn{4}{|c|}{ LDPE Content } & \multirow{2}{*}{ Unit } & \multirow{2}{*}{ Requirment } \\
\cline { 3 - 6 } & $\mathbf{0 \%}$ & $\mathbf{3 \%}$ & $\mathbf{5 \%}$ & $\mathbf{7 \%}$ & & Min. 1 \\
\hline 2 & $\begin{array}{l}\text { Specific } \\
\text { gravity }\end{array}$ & 1.03 & 1.026 & 1.028 & 1.209 & - & $60-70$ \\
\hline 3 & Penetration & 65 & 63 & 62 & 61 & $\mathrm{~mm}$ & Min. 100 \\
\hline 4 & $\begin{array}{l}\text { Ductility } \\
\text { Poftening }\end{array}$ & 49.5 & 53 & 52 & 54.8 & ${ }^{\circ} \mathrm{C}$ & Min. 48 \\
\hline
\end{tabular}

\section{3) Coconut-shell Ash (CA)}

$\mathrm{CA}$ is the remaining combustion from charcoal that has become ash, black to grey, usually odourless and tasteless. This ash is in the form of soil or mineral material such as silica. Analysis of ash content was carried out by taking samples of charcoal that had been weighed first so that a constant mass of about 1 gram was obtained and then the sample was heated for 3 hours at $900^{\circ} \mathrm{C}$. After completion, the sample is then cooled and weighed again, so that the ash content is obtained from the results of the mass of ash with the mass of the sample results of heating and multiplied by $100 \%$.

Activated carbon is a material that has very many pores that function to absorb everything it passes. One of them is activated carbon material that comes from animals, plants or minerals that contain carbon, among others, from CA, hard wood, palm oil, there are also those from coal, bone, bagasse, sawdust and so on [13].

Table- III: Physical Properties of Aggregate

\begin{tabular}{|c|l|c|}
\hline No. & \multicolumn{1}{|c|}{ Chemical Compound } & Percentage \\
\hline 1. & Silicon dioxide $(\mathrm{SiO} 2)$ & 7,40 \\
\hline 2. & Calsium Oksida $(\mathrm{CaO})$ & 1,43 \\
\hline 3. & Magnesium Oxide $(\mathrm{MgO})$ & 2,78 \\
\hline 4. & Iron(III) oxide $(\mathrm{Fe} 2 \mathrm{O} 3)$ & 1,74 \\
\hline 5. & Silicate $(\mathrm{SiO} 3)$ & 8,20 \\
\hline 6. & Sulfate ion $(\mathrm{SO} 4)$ & 0,57 \\
\hline
\end{tabular}

There are 4 ways of burning coconut shells, including the method of combustion on the ground directly, the method of combustion in oil drums, the combustion method in the combustion chamber of bricks and the combustion method in cylindrical metal drums heat resistant.

\section{4) Plastic Low Density Polyethylene (LDPE)}

The most common polymer in plastic is polyethylene which is produced (made) from ethylene monomers $\left(\mathrm{CH}_{2}=\mathrm{CH}_{2}\right)$. First made is LDPE. This material floats in a mixture of water and alcohol. The characteristics of LDPE are soft and flexible so that it was first applied as an electrical wire insulator, but now the application has developed including filmmaking, food wraps, bottles, garbage bags, and disposable gloves [14].

Based on these characteristics, many researchers have conducted research on the use of LDPE plastic waste as an ingredient to increase the quality of asphalt (asphalt modifier). Researchers examined the effect of adding LDPE plastic to the asphalt pen. $60 / 70$ with variations in plastic content of $3 \% ; 3.5 \%$; and $4 \%$ towards the rheology properties of asphalt, penetration testing and softening point were carried out. The test results show that adding plastic to the asphalt increases the softening point and decreases the penetration value. Thus the asphalt is not sensitive to changes in temperature or increased index penetration values which in turn will increase the durability of the pavement against deformation.

\section{B. Experimental Plan}

There are some stages carried out in this study. First is preparing materials and tools needed, as well as examining physical properties of aggregate and asphalt and sieving. If the results of examination of physical properties of the material meet the specifications, then proceed with the manufacture of the test object. The test material to be made consists of three groups, namely:

- The asphalt mixture is porous with $60 / 70$ penetration asphalt 
and cement filler for optimum asphalt content determination (OAC). OAC determination uses the Australian method with the parameters of the cantabro loss value, asphalt flow down and voids in mix.

- After OAC is obtained, then the test object is made at $\mathrm{OAC}$ and the variation of $\mathrm{OAC} \pm 0.5$ with $50 \% \mathrm{CA}$ as filler substitution material and LDPE plastic waste as substitution asphalt pen. $60 / 70$ of $3 \%, 5 \%$ and $7 \%$ of the asphalt weight.

- Test material for testing permeability and durability at the best bitumen level.

- From the results of Marshall Tests, cantabro loss and AFD on each variation in the percentage of LDPE plastic waste with each type of asphalt, then it will be compared for each parameter and draw conclusions regarding the effect of using CA and LDPE plastic waste for porous asphalt mixtures.

- From the results of Marshall Tests, cantabro loss and AFD on each variation in the percentage of LDPE plastic waste with each type of asphalt, then it will be compared for each parameter and draw conclusions regarding the effect of using $C A$ and LDPE plastic waste for porous asphalt mixtures.

\section{1) Marshall Test}

This test is performed to define the resistance (stability) to the flow from the asphalt mixture. This test is based on AASTO-245-74. The tool used is a Marshall Test equipment complete with stability and flow dial, water bath, thermometer, callipers and open scales.

The making of the test object is done by mixing the asphalt with aggregate at the mixing temperature according to the requirements of $160^{\circ} \mathrm{C}$. The test object is inserted into the mould then compressed by pulverizing 50 times per field using a Marshall pounder at a compaction temperature of 150 ${ }^{\circ} \mathrm{C}$.

After the specimen is compacted, then stored at room temperature for 24 hours, then the test object is weighed in the air, in water and in a saturated surface dry (SSD) condition to obtain the weight of the test specimen. Then the test object was soaked at a temperature of $60 \mathrm{oC}$ for 30 minutes and ready for stability and flow testing using the Marshall Test equipment.

Marshall Tests include stability test, plastic melt (flow), weight, density, VIM and Marshall Quotient. In testing durability the bitumen content used is the best bitumen content. Durability testing is intended to see the durability of the test specimen. Durability criteria obtained through testing Marshall Immersion stability, namely the stability of the test object soaked for 24 hours at $60^{\circ} \mathrm{C}$. The ratio between Marshall Immersion stability and Marshall Stability of the test object soaked for 30 minutes at the same temperature is called residual stability. Paved mixture is durable, if the residual stability value is $\geq 90 \%$.

\section{2) Cantabro Loss Test}

Abrasion resistance was determined using Cantabro Loss Test in the laboratory from Marshall Specimens. This test is also performed to determine the strength of the asphalt mixture against the disintegration process or the release resistance of graded open mixtures.
Making the cantabro loss object is the same as in the Marshall Test object, the test object is first made 50x collisions on each side. The test object is then placed in a Los Angeles machine and rotated as many as 300 turns without using a steel ball. The test object used is a test object that is 7 days old.

\section{3) Asphalt Flow Down Test}

Asphalt flow down testing is intended to determine the maximum asphalt content that can be mixed homogeneously with the aggregate without the asphalt separation. This is important so that during the transportation of AMP (asphalt mixing plant) to the location of the asphalt separation does not occur. Asphalt flow down testing procedures is as follows:

- Mould in the form of a tray with a surface size of $20 \times 20$ $\mathrm{cm}$ coated with paperboard, the weight of the mold + cardboard is weighed and recorded (m1);

- Then made asphalt mixture weighing \pm 600 gr and after evenly mixed poured over the previously coated mold, the surface leveled and recorded weight (m2);

- The mold containing the asphalt mixture was put into an oven with a temperature of $\pm 160 \mathrm{C}$ for \pm 60 minutes.

- The procedure is repeated as needed;

- The mold is removed from the oven and the asphalt mixture is poured quickly, then the weight of the mold and the asphalt mixture attached to the paperboard are weighed and recorded $\left(\mathrm{m}^{3}\right)$.

\section{RESUlT AND DISCUSSION}

The results of the study presented are the results of the evaluation of the use of LDPE as a substitute material for $60 / 70$ pen asphalt for the characteristics of porous asphalt mixtures. But besides that, data will also be presented on the results of examination of the materials used in the mixture as a support in evaluating the effect of the use of LDPE on the characteristics of porous asphalt mixture which includes the results of examination of aggregate physical properties, examination results of asphalt physical properties, Marshall test results, cantabro loss test results, asphalt flow down test results, on asphalt content variations $4.5 \%, 5.0 \%, 5.5 \% .6 .0 \%$ and $6.5 \%$ to obtain OAC of porous asphalt mixture and parameter evaluation, Marshall, CL and AFD in Variations \pm 0.5 of OAC values.

The significant factors that affecting the testing result were identified by using Analysis of Variant (ANOVA). It was calculated using the aid of Microsoft ${ }^{\circledR}$ Excel ${ }^{\circledR}$ software.

In the ANOVA Test, it is assumed that all sample averages are the same ( $\mathrm{H} 0 /$ null hypothesis) by choosing a confidence interval of $95 \%(\alpha=0.05)$. P value calculated must be smaller than 0.05 (H0 rejected) which means there is a significant result differences on the variable.

\section{A. Effect of LDPE Substitution to Cantabro-loss}

Based on ANOVA analysis the p-value for Cantabro loss testing result is 1.03E-07 thus it implies that in this study the different LDPE waste content have result in significance Cantabro loss value. 
However only the mixture with 3\% LDPE waste content that satisfy the specification of lower than $20 \%$.

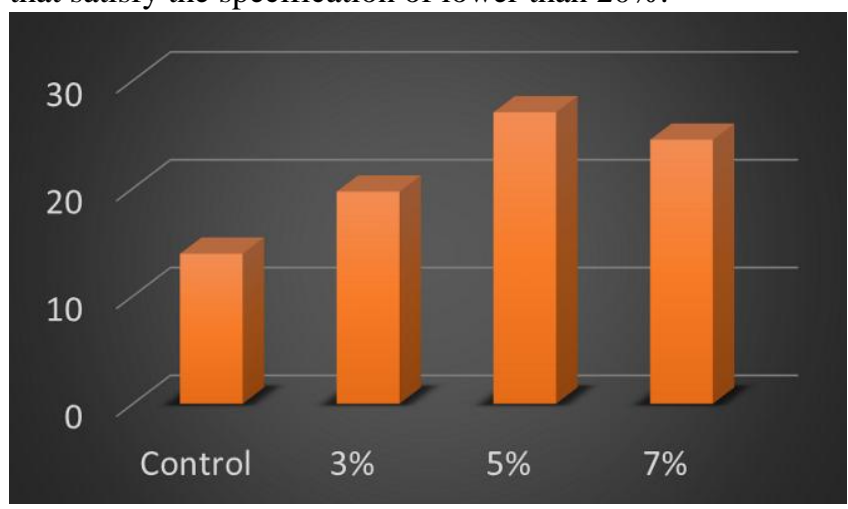

Fig. 1.Cantrabro Loss Result of Different LDPE Waste Content

\section{B. Effect of LDPE Substitution to Asphalt Flow Down}

Although all combination of LDPE waste substitution satisfy AAPA specification for porous asphalt. The different LDPE waste content result in different asphalt flow down value and it value between each of them in this study is statistically significance with $\mathrm{P}$ value lower than 0.5 .

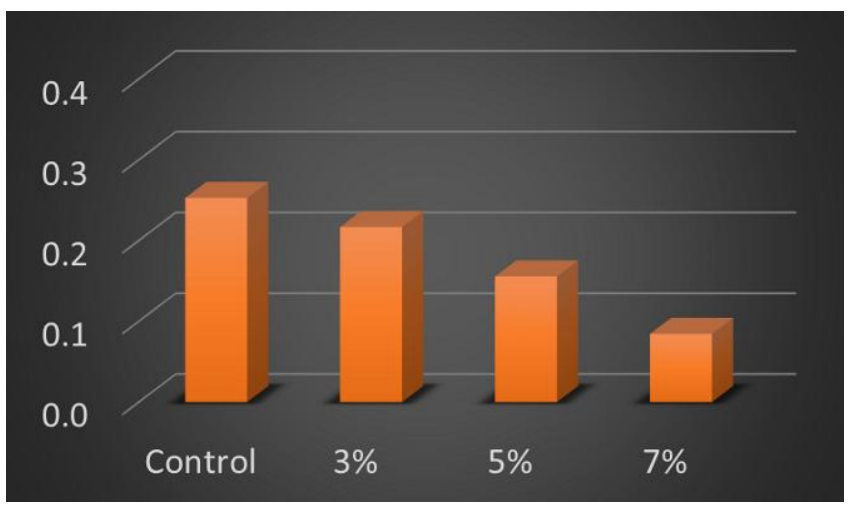

Fig. 2.Asphalt Flow Down Result of Different LDPE Waste Content

\section{Effect of LDPE Substitution to Marshall Stability, VIM, Flow and Marshall Quotient}

Figure below shows respectively for Flow, Marshall Stability, VIM and Marshall Quotient testing results ordered by the percentage of LDPE waste used as asphalt substitution. Even though there seems to be clear decreasing trend in term of Marshall Stability by the increasing of LDPE waste content as binder substitute, there are statistically no significant different in all above mentioned testing result due to the $\mathrm{p}$ value in each testing result are higher than 0.05 . The result from ANOVA analysis are, 0.04, 0.03, and 0. 0.2 for Marshall Stability, Flow, and VIM testing result respectively.

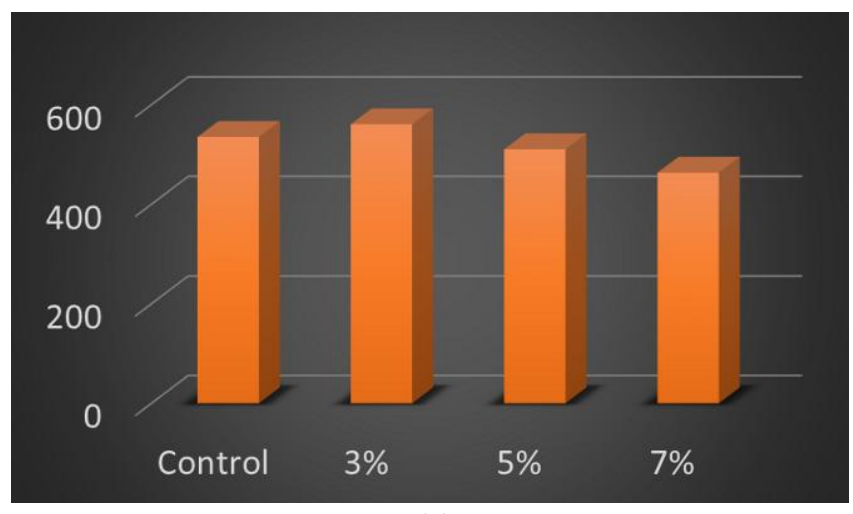

(a)

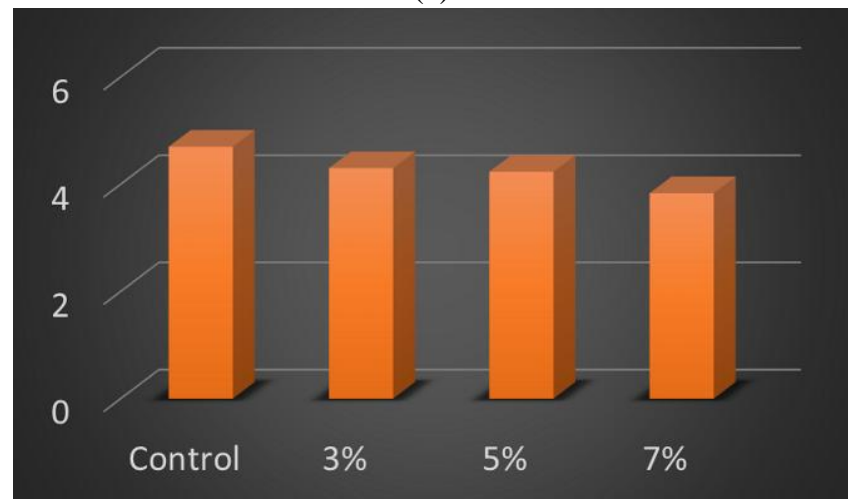

(b)

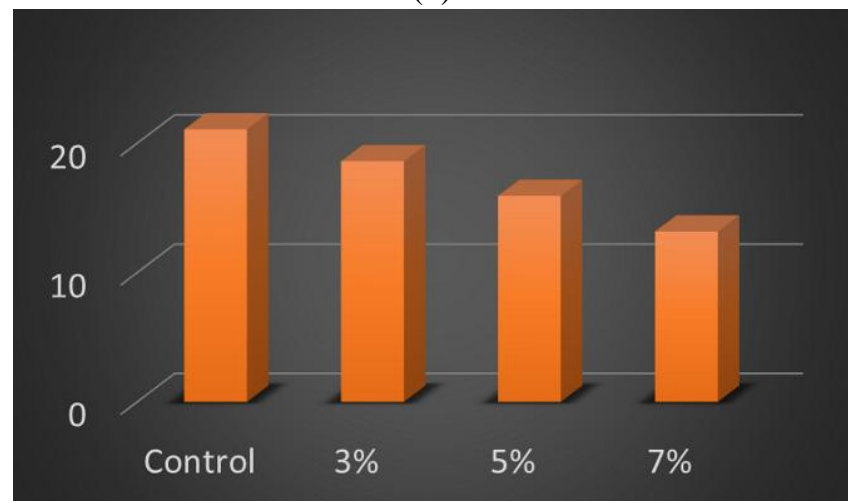

(c)

Fig. 3.(a) Marshall Stability, (b) Flow, and (c) VIM Testing Result

\section{CONCLUSION}

1) Based on the evaluation of Marshall parameters, Asphalt Flow Down (AFD) and Cantabro Loss (CL), the optimum asphalt content $(\mathrm{OAC})$ value of porous asphalt mixture is $5.76 \%$ and the best Asphalt Content is at 3\% LDPE + CA $50 \%$ substitution.

2) All the specimen in this study meet the requirement for AFD and CL criteria based on AAPA specification (2004).

3) It is evidence that with the increase the percentage of LDPE content in the mixture AFD value will decrease.

4) In contrary CL testing value indicate that by increasing the percentage of LDPE content the CL value decrease. However, the CL testing result started decreasing at $7 \%$ LDPE content. 
5) Stability values in mixed asphalt levels tend to increase with substitution of LDPE + CA compared with the bitumen content without substitution of LDPE + CA. the highest stability value is found in the percentage with $3 \%$ LDPE substitution and 50\% CA with the highest stability value of $560.50 \mathrm{~kg}$.

6) Flow values decrease with increasing percentage of LDPE substitution. The lowest value at $7 \%$ substitution of LDPE $+50 \% \mathrm{CA}$ is $3.83 \mathrm{~mm}$.

7) At the VIM value the percentage that meets the requirements of the AAPA standard value (2004), at 3\%

\section{REFERENCES}

1. Syammaun, T. and H. Rani. Resilient modulus of porous asphalt using oil palm fiber. in IOP Conference Series: Materials Science and Engineering. 2018. IOP Publishing.

2. Association, A.A.P., National asphalt specification. 2004: The Association.

3. Norhafizah, M. and M.R. Hainin, The effect of coconut shell on engineering properties of porous asphalt mixture. Jurnal Teknologi, 2016. 78(7-2)

4. Punith, V., A. Veeraragavan, and S.N. Amirkhanian, Evaluation of reclaimed polyethylene modified asphalt concrete mixtures. International Journal of Pavement Research and Technology, 2011. 4(1): p. 1-10.

5. Yan, K., H. Xu, and L. You, Rheological properties of asphalts modified by waste tire rubber and reclaimed low density polyethylene. Construction and Building Materials, 2015. 83: p. 143-149.

6. Lastra-González, P., et al., Comparative analysis of the performance of asphalt concretes modified by dry way with polymeric waste. Construction and Building Materials, 2016. 112: p. 1133-1140.

7. García-Travé, G., et al., Use of reclaimed geomembranes for modification of mechanical performance of bituminous binders. Journal of Materials in Civil Engineering, 2016. 28(7): p. 04016021.

8. Karmakar, S. and T.K. Roy, Effect of waste plastic and waste tires ash on mechanical behavior of bitumen. Journal of Materials in Civil Engineering, 2016. 28(6): p. 04016006.

9. Modarres, A. and H. Hamedi, Effect of waste plastic bottles on the stiffness and fatigue properties of modified asphalt mixes. Materials \& Design, 2014. 61: p. 8-15.

10. Wang, J., et al., Performance investigation and sustainability evaluation of multiple-polymer asphalt mixtures in airfield pavement. Journal of Cleaner Production, 2018. 189: p. 67-77.

11. Giri, J.P., M. Panda, and U.C. Sahoo, Performance of Bituminous Mixes Containing Treated Recycled Concrete Aggregates and Modified by Waste Polyethylene. Journal of Materials in Civil Engineering, 2018. 30(8): p. 04018184.

12. Al-Mansob, R.A., et al., Comparison between mixtures of asphalt with Palm Oil Shells and coconut Shells as additives. Jurnal Kejuruteraan, 2013. 25: p. 25-31.

13. Shelke, A.S., et al., Coconut Shell as Partial Replacement for Coarse Aggregate: Review. International Journal of Civil Engineering Research, 2014. 5(3): p. 211-214.

14. Wong, S., et al. Utilization of waste plastics in stone mastic asphalt for infrastructural applications. in Materials Science Forum. 2017. Trans Tech Publ.

\section{AUTHORS PROFILE}

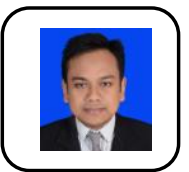

I got my bachelor degree in 2007 from Faculty of Civil Engineering at Syiah Kuala University in Banda Aceh, Indonesia. Then continued master degree at the University of Malaya, in Malaysia and graduated in 2013. When taking my master's degree, I focused my research on the field of highway pavement, with the title of the thesis "Effect of oil palm fiber on some physical properties of porous asphalt".

In research and publication, I have produced several paper including Dynamic properties of stone mastic asphalt mixtures containing waste plastic bottles published by Construction and Building Materials (2012), Resilient Modulus of Porous Asphalt using Palm Fiber Oil in IOP Conf. Series: Materials Science and Engineering (2018) and the last in this year is The Effect of field aging on adhesive properties of warm-mix asphalt, published by the American Institute of Physics Conference in 2019.
Currently I work as a Lecturer in the Civil Engineering Study Program at the University of Muhammadiyah Aceh in Banda Aceh, Indonesia. I teach courses related to the field of Road and Transportation. Apart from my academics experience, I am also part of a number of organizations such as the Indonesian Professional Engineer Program and the Disaster Mitigation at Faculty of Engineering, University of Muhammadiyah Aceh.

Throughout my career, I have worked professionally including when the tsunami hitted Aceh, Indonesia. Joining the international NGOs, I participated in the rehabilitation and reconstruction of Aceh after the Tsunami.

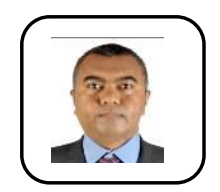

Firmansyah Rachman Starting my bachelor degree in Civil Engineering Faculty of Syiah Kuala University in Banda Aceh, Indonesia, I obtained my bachelor degree in 2009. With endless support from my family, friends and my advisor I succeeded in obtaining my Master Degree from National Cheng Kung University (NCKU) Civil Engineering Department with the support of Aceh's Government Scholarship.

During my master degree, I developed my knowledge in sustainable pavement materials. The thesis title that I choose was "The Effect of Moisture Presence in Aggregate to Asphalt-Aggregate Adhesive Properties of Warm-Mix Asphalt".

During the past two years, my team and I have succeed to generate two paper out of my thesis research. In 2018, my advisor and I have publish a paper at Q1 journals, Construction and Building Materials. The title for this paper is "Effect of moisture in aggregate on adhesive properties of warm-mix asphalt". The other one is titled "Effect of field aging on adhesive properties of warm-mix asphalt", this paper was publish in American Institute of Physics Conference in 2019.

Apart from that, my team and I have also conducted small-scale research that closely related to pavement materials that we presented in several international conference such as: "Characteristic of coconut-shell ash as filler and LDPE plastic waste as substitution materials of porous asphalt mixtures" at International Seminar on Sustainable Construction Engineering 2019, and "Evaluation of Asphalt Porous Mixture Properties due to Addition of Arenga Pinnata Fibers and Coconut Fibers" at $2^{\text {nd }}$ International Conference on Engineering and Applied Technology (ICEAT) 2018.

I have practice variety of working environment during my more than 13 years professional work life, thus it has broaden my horizon in professional work experience and has helped me to be able to become accustomed in different working environment relatively easier. I've been working at profit or non-profit organization/company whether it's international or local NGOs, government project and finally in academic research field.

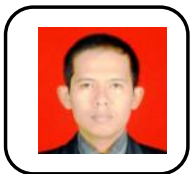

Rifki Hidayat, ST. MT, born in Bayur (West Sumatra), November 1st 1986, completed his bachelor degree in Civil Engineering at Faculty of Engineering, Department of Civil Engineering, Syiah Kuala University, Banda Aceh, in 2010 in the field of Geotechnics. The title of his final research project is "The Effect of Coconut Shell Ash Addition to Soil Behaviour in Cot Seunong village Montasik.

In 2013 continued the Masters degree in Transportation Engineering Management, the thesis focused on research in the laboratory of highway in Syiah Kuala University with the title, "Characteristics Test of Coconut Shell Ash Mixture as a Filler Substitution Material and LDPE Plastic Waste as an Asphalt Pen. 60/70 Substitution Material On the Performance of Porus Asphalt Mixture.

In 2010 began working in planning consultants for one year, and in 2012 participated PNPM community empowerment program in Sabang for one year, in 2013 to 2018 working in the Faculty of Engineering, University of Muhammadiyah Aceh as a laboratory assistant at Soil Mechanics laboratory.

In 2019, he starts working as a lecturer in Faculty of Civil Engineering at University of Muhammadiyah Aceh in the field of Transportation, on subjects of Road Pavement Engineering, Road Pavement Practicum, Engineering Geology, and Drawing on Buildings I and II 